\title{
Article \\ On Optimal Barium Promoter Content in a Cobalt Catalyst for Ammonia Synthesis
}

\author{
Aleksandra Tarka ${ }^{1}$, Magdalena Zybert $^{1}{ }^{\circledR}$, Hubert Ronduda $^{1}\left({ }^{\circledR}\right.$, Wojciech Patkowski $^{1} \oplus$, Bogusław Mierzwa $^{2}$, \\ Leszek Kęiński ${ }^{3}$ and Wioletta Raróg-Pilecka ${ }^{1, *}$
}

1 Faculty of Chemistry, Warsaw University of Technology, Noakowskiego 3, 00-664 Warsaw, Poland; aleksandra_tarka@interia.pl (A.T.); magdalena.zybert@pw.edu.pl (M.Z.);

hubert.ronduda.dokt@pw.edu.pl (H.R.); wpatkowski@ch.pw.edu.pl (W.P.)

2 Institute of Physical Chemistry, Polish Academy of Sciences, Kasprzaka 44/52, 01-224 Warsaw, Poland; bmierzwa@ichf.edu.pl

3 Institute of Low Temperature and Structure Research, Polish Academy of Sciences, Okólna 2, 50-950 Wrocław, Poland; 1.kepinski@intibs.pl

* Correspondence: wiola@ch.pw.edu.pl; Tel.: +48-22-2345766

Citation: Tarka, A.; Zybert, M.; Ronduda, H.; Patkowski, W.; Mierzwa, B.; Kepiński, L.; Raróg-Pilecka, W. On Optimal Barium Promoter Content in a Cobalt Catalyst for Ammonia Synthesis. Catalysts 2022, 12, 199. https:// doi.org/10.3390/catal12020199

Academic Editor: Benoît Louis

Received: 30 December 2021

Accepted: 3 February 2022

Published: 6 February 2022

Publisher's Note: MDPI stays neutral with regard to jurisdictional claims in published maps and institutional affiliations.

Copyright: (c) 2022 by the authors. Licensee MDPI, Basel, Switzerland. This article is an open access article distributed under the terms and conditions of the Creative Commons Attribution (CC BY) license (https:/ / creativecommons.org/licenses/by/ $4.0 /)$.

\begin{abstract}
High priority in developing an efficient cobalt catalyst for ammonia synthesis involves optimizing its composition in terms of the content of promoters. In this work, a series of cobalt catalysts doubly promoted with cerium and barium was prepared and tested in ammonia synthesis $\left(\mathrm{H}_{2} / \mathrm{N}_{2}=3,6.3 \mathrm{MPa}, 400{ }^{\circ} \mathrm{C}\right)$. Barium content was studied in the range of $0-2.6 \mathrm{mmol} \mathrm{g}_{\mathrm{Co}}{ }^{-1}$. Detailed characterization studies by nitrogen physisorption, SEM-EDX, XRPD, $\mathrm{H}_{2}-\mathrm{TPR}$, and $\mathrm{H}_{2}$-TPD showed the impact of barium loading in $\mathrm{CoCeBa}$ catalysts on the physicochemical properties and activity of the catalysts. The most pronounced effect was observed in the development of the active phase surface, a differentiation of weakly and strongly binding sites on the catalyst surface and changes in cobalt surface activity (TOF). Barium content in the range of $1.1-1.6 \mathrm{mmol} \mathrm{g}_{\mathrm{Co}}{ }^{-1}$ leads to obtaining a catalyst with the most favorable properties. Its excellent catalytic performance is ascribed to the appropriate $\mathrm{Ba} / \mathrm{Ce}$ molar ratio, i.e., greater than unity, which results in not only a structural promotion of barium, but also a modifying action associated with the in-situ formation of the $\mathrm{BaCeO}_{3}$ phase.
\end{abstract}

Keywords: ammonia synthesis; cobalt catalyst; barium; promoter; optimization

\section{Introduction}

Many industrial processes require the use of catalysts to carry out a reaction at a suitable rate and under desirable conditions. A classic example of heterogeneous catalysis is ammonia synthesis over Fe- or Ru-based catalysts. These metals alone are almost inactive in ammonia synthesis [1-3], but their activity significantly increases in the presence of some compounds. These compounds, added to catalysts in small amounts, are called promoters, and they play a crucial role in heterogeneous catalysis [4]. They improve catalyst properties by enhancing activity, lifespan (long-term stability), and selectivity. Promoters can be divided into structural and electronic promoters, depending on the mode of their action. Structural promoters primarily increase the catalyst's activity by increasing the surface area of an active phase. Electronic (chemical) promoters increase the catalytic activity by modifying the active metal and by increasing the reaction rate per surface area $[5,6]$. This is a general description, but the function of each promoter is always specific to the particular catalytic system and the particular reaction.

In the case of a fused iron catalyst for ammonia synthesis, aluminum oxide, calcium oxide, and magnesium oxide are typically used as structural promoters [7]. They stabilize the active planes of the metal (role of $\mathrm{Al}_{2} \mathrm{O}_{3}$ ), increase and stabilize the catalyst surface area during reduction (role of $\mathrm{CaO}$ and $\mathrm{MgO}$ ), and increase the catalyst resistance to impurities (role of $\mathrm{CaO}$ ). Moreover, potassium oxide is used as an electronic promoter. It 
can increase the rate-limiting step of dissociative nitrogen adsorption [8] or decrease the concentration of produced ammonia adsorbed on the iron surface, and hence make more active sites available for nitrogen [9]. In the case of ruthenium, alkali metals are electronic promoters whose influence is similar to that noted for the iron catalyst [2,10-12]. High activity in ammonia synthesis was also achieved by promoting ruthenium by cesium and barium $[13,14]$.

Among the alkaline earth metals, barium is of particular attention as a very effective promoter of catalysts for the synthesis of ammonia [15-27]. Its role is significant and has been thoroughly investigated by many researcher groups, but its effect has not been fully explained. Some authors have shown that it is a structural promoter [18-20], whereas others postulate that it exhibits an electronic effect [21-23]. There is also a viewpoint in which the influence of barium may have a mixed character, i.e., both structural and electronic $[15,24,27]$. A cobalt catalyst doubly promoted with cerium and barium was the subject of our previous research $[15,27]$. These cobalt-cerium-barium systems exhibited very high activity in ammonia synthesis. The studies revealed that the double promotion of cobalt with $\mathrm{Ce}$ and Ba causes an approximately twofold increase in catalyst activity, compared to the cobalt system promoted only with barium, and over tenfold increase in activity compared to the cobalt system doped only with cerium. The particularly beneficial properties of the catalyst result from the synergistic action of the two promoters. Cerium oxide is a structural promoter in cobalt-cerium-barium systems preventing Co particles from sintering during the reaction and stabilizing the active hcp cobalt phase [15,27-29]. Optimal cerium oxide content $\left(1.0 \mathrm{mmol} \mathrm{g}_{\mathrm{Co}}{ }^{-1}\right)$, i.e., one which provides the most favorable catalytic properties, was determined during our further studies [28]. In the case of barium, although it mainly exhibits an electronic character, structural effects have been observed. However, the most important is the participation in the in-situ formation (under the conditions of catalysts activation) of the $\mathrm{BaCeO}_{3}$ phase. It is the third promoter with strong electron-donating properties and the ability to differentiate the structure of hydrogen adsorption sites (co-existence of weakly and strongly binding sites) on the active phase surface. However, these observations were carried out only for one catalyst composition (Ce content $1.0 \mathrm{mmol} \mathrm{g}_{\mathrm{Co}}{ }^{-1}$, Ba content $1.4 \mathrm{mmol} \mathrm{g}_{\mathrm{Co}}{ }^{-1}$ ) $[15,27]$.

As a continuation of the systematic studies of barium-promoted cobalt catalysts, in this work, we studied ammonia synthesis on doubly promoted cobalt-cerium-barium catalysts of various barium content (in the range of $0-2.6 \mathrm{mmol} \mathrm{g}_{\mathrm{Co}}{ }^{-1}$ ). The main goal was to determine the optimal content of the barium promoter, providing the most favorable catalytic properties of the studied CoCeBa systems. Thorough characterization studies of the prepared materials by nitrogen physisorption, Scanning Electron Microscopy with Energy Dispersive Spectroscopy (SEM-EDX), X-ray Powder Diffraction (XRPD), TemperatureProgrammed Reduction with hydrogen $\left(\mathrm{H}_{2}-\mathrm{TPR}\right)$, and Temperature-Programmed Desorption of hydrogen $\left(\mathrm{H}_{2}\right.$-TPD) were used to determine the influence of the barium content on the properties and catalytic performance of the doubly promoted cobalt catalysts in ammonia synthesis.

\section{Results and Discussion}

\subsection{Textural Characteristics ( $\mathrm{N}_{2}$ Physisorption)}

The textural characteristics of the catalyst precursors are summarized in Table 1. A small addition of the barium promoter $\left(0.2 \mathrm{mmol} \mathrm{gCo}^{-1}\right)$ results in a decrease of the specific surface area $\left(\mathrm{S}_{\mathrm{BET}}\right)$ of the precursor by about $11 \%$ and an over twofold decrease of the total pore volume $\left(\mathrm{V}_{\mathrm{P}}\right)(\mathrm{CoCeBa}(0.2))$, compared to that of the precursor without barium $(\mathrm{CoCe})$. When the barium content in samples is increased to $1.4 \mathrm{mmol} \mathrm{Ba} \mathrm{gCo}^{-1}$, a further decrease in $\mathrm{S}_{\mathrm{BET}}$ and $\mathrm{V}_{\mathrm{P}}$ values is observed, which is probably a result of filling pores with

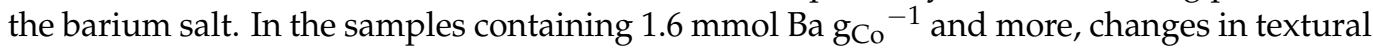
parameters $\left(\mathrm{S}_{\mathrm{BET}}, \mathrm{V}_{\mathrm{P}}\right)$ are negligibly small. Selected precursors of small, medium, and high Ba content were reduced in-situ, and their specific surface areas were measured (Table 1 , $S_{R}$ values). A significant decrease in a specific surface area of the materials is observed 
due to reduction. For example, the surface of the CoCe sample decreases after reduction over 11 times, and in the case of $\mathrm{CoCeBa}(2.6)$, the specific surface area after reduction is nearly 22-times smaller than before the reduction. For $\mathrm{CoCeBa}(1.4)$ e, the specific surface area after reduction was only 5 times lower. This indicates that barium has a beneficial effect when added in an optimal amount and effectively prevents sintering of the grains during reduction. The increase of the specific surface area with an increase of the barium content is observed for samples containing $0.2-1.4 \mathrm{mmol} \mathrm{Ba} \mathrm{g}_{\mathrm{Co}}{ }^{-1}$. The $\mathrm{S}_{\mathrm{R}}$ value for the reduced sample promoted by a small amount of barium $(\mathrm{CoCeBa}(0.2))$ is approximately $9 \%$ larger than the surface area of the reduced sample without barium $(\mathrm{CoCe})$. The highest $S_{R}$ value after reduction is observed for $\mathrm{CoCeBa}(1.4)$. Further increase of barium content, i.e., over $1.4 \mathrm{mmol} \mathrm{Ba} \mathrm{g}_{\mathrm{Co}}{ }^{-1}$, caused a decrease in the surface area of the reduced samples. The observed effects indicate that barium may behave as a structural promoter. However, there is an optimum content of $\mathrm{Ba}$, which may develop the catalyst surface. After exceeding it, the catalyst grains sinter, resulting in decrease of the specific surface area of the catalysts.

Table 1. Chemical composition and textural parameters of the promoted cobalt catalysts.

\begin{tabular}{|c|c|c|c|c|c|}
\hline Catalyst & Ba Content ${ }^{1}\left(\mathrm{mmol} \mathrm{g}_{\left.\mathrm{Co}^{-1}\right)}\right.$ & Ba/Ce Molar Ratio ${ }^{2}$ & $\mathrm{~S}_{\mathrm{BET}}{ }^{3}\left(\mathrm{~m}^{2} \mathrm{~g}^{-1}\right)$ & $S_{R}{ }^{4}\left(m^{2} g^{-1}\right)$ & $V_{P}{ }^{5}\left(\mathrm{~cm}^{3} \mathrm{~g}^{-1}\right)$ \\
\hline $\mathrm{CoCe}$ & 0.00 & - & 85 & 7.5 & 0.34 \\
\hline $\mathrm{CoCeBa}(0.2)$ & 0.20 & 0.2 & 76 & 8.2 & 0.15 \\
\hline $\mathrm{CoCeBa}(0.5)$ & 0.48 & 0.4 & 67 & - & 0.14 \\
\hline $\mathrm{CoCeBa}(1.1)$ & 1.05 & 0.9 & 63 & - & 0.14 \\
\hline $\mathrm{CoCeBa}(1.4)$ & 1.36 & 1.2 & 52 & 10.7 & 0.12 \\
\hline $\mathrm{CoCeBa}(1.6)$ & 1.61 & 1.4 & 52 & - & 0.12 \\
\hline $\mathrm{CoCeBa}(2.0)$ & 1.95 & 1.7 & 53 & 5.0 & 0.15 \\
\hline $\mathrm{CoCeBa}(2.2)$ & 2.19 & 2.0 & 52 & 4.9 & 0.15 \\
\hline $\mathrm{CoCeBa}(2.6)$ & 2.62 & 2.3 & 52 & 2.4 & 0.14 \\
\hline
\end{tabular}

${ }^{1}$ Values determined based on mass balance after impregnation of the $\mathrm{Co}_{3} \mathrm{O}_{4}+\mathrm{CeO}_{2}$ sample. ${ }^{2}$ Cerium content is constant and equal to $1.1 \mathrm{mmol} \mathrm{g} \mathrm{Co}^{-1}$, the value calculated based on the cerium oxide content in the $\mathrm{Co}_{3} \mathrm{O}_{4}+\mathrm{CeO}_{2}$ sample determined using TG-MS. ${ }^{3} \mathrm{~S}_{\mathrm{BET}}$-specific surface area estimated based on the BET isotherm model ${ }^{4} \mathrm{~S}_{\mathrm{R}}$-specific surface area estimated based on the BET isotherm model after hydrogen activation. ${ }^{5} \mathrm{~V}_{\mathrm{P}}$-total pore volume estimated based on the $\mathrm{BJH}$ isotherm model.

\subsection{Reduction Behavior of the Studied Catalysts $\left(\mathrm{H}_{2}-\mathrm{TPR}\right)$}

In order to investigate the effect of the barium promoter content on the reducibility of the cobalt catalysts, temperature-programmed reduction measurements were performed. Figure 1 shows the reduction profiles for the studied catalysts. The area of the graph presented in Figure 1 was divided into areas marked as I, II, IIIa, and IIIb to simplify the description of the obtained signals. In the reduction profile of the CoCe sample, which in the oxidized form is a mixture of $\mathrm{Co}_{3} \mathrm{O}_{4}$ and $\mathrm{CeO}_{2}$ oxides, two peaks (marked in Figure 1 as II and III) are observed, with maxima at $289^{\circ} \mathrm{C}$ and $479{ }^{\circ} \mathrm{C}$, respectively. These signals correspond to a two-step reduction of cobalt oxide to metallic cobalt $[30,31]$, in accordance with Equations (1) and (2):

$$
\begin{gathered}
\mathrm{Co}_{3} \mathrm{O}_{4}+\mathrm{H}_{2} \rightarrow 3 \mathrm{CoO}+\mathrm{H}_{2} \mathrm{O} \\
3 \mathrm{CoO}+3 \mathrm{H}_{2} \rightarrow 3 \mathrm{Co}+3 \mathrm{H}_{2} \mathrm{O}
\end{gathered}
$$

Under the measurement conditions (temperature increase from 30 to $700{ }^{\circ} \mathrm{C}$ at a constant rate of $10^{\circ} \mathrm{C} \mathrm{min}^{-1}, 10 \mathrm{vol} . \% \mathrm{H}_{2} / \mathrm{Ar}$ ), cerium (IV) oxide did not undergo reduction, which has been reported in previous studies $[15,28]$. It is noted that the introduction of the barium promoter to the systems containing cobalt (II,III) oxide and cerium (IV) oxide causes a change in the course of their reduction (Figure 1). The TPR profiles of the samples containing barium show a small peak (I) of constant area and maximum in the range of $210{ }^{\circ} \mathrm{C} \pm 15^{\circ} \mathrm{C}$, which may be related to the decomposition of the barium salt. The position of peak II is not influenced by the barium content in the system. Its maximum occurs at the temperature of $299^{\circ} \mathrm{C} \pm 8{ }^{\circ} \mathrm{C}$. However, in the case of the samples containing barium in the 
amount of $1.4 \mathrm{mmol} \mathrm{g}_{\mathrm{Co}}{ }^{-1}$ and more, the intensity of peak II slightly increases. Presumably, it results from the overlapping of the peaks related to the reduction of $\mathrm{Co}_{3} \mathrm{O}_{4}$ to $\mathrm{CoO}$ and further decomposition of the barium salt. In the profiles of the samples containing 0.2-1.1 mmol Ba $\mathrm{g}_{\mathrm{Co}}{ }^{-1}$, the maximum of peak III shifts towards higher temperatures with increasing barium promoter content. For the samples containing $1.4 \mathrm{mmol} \mathrm{Ba} \mathrm{gCo}^{-1}$ and more, two peaks (IIIa and IIIb) are observed instead of one in the region where peak III is present. The maximum of peak IIIa occurs in a constant temperature range, i.e., $435{ }^{\circ} \mathrm{C} \pm 5{ }^{\circ} \mathrm{C}$, while the maximum of peak IIIb shifts from the position at $554{ }^{\circ} \mathrm{C}$ for $\mathrm{CoCeBa}(1.4)$ towards lower temperatures with increasing barium content. Moreover, with the addition of more barium promoter, the decrease in the intensity of peak IIIb is observed, accompanied by the increase in the intensity of peak IIIa. Finally, in the reduction profile of $\mathrm{CoCeBa}(2.6)$, a very high intensity of peak IIIa and a negligibly small IIIb peak are observed.

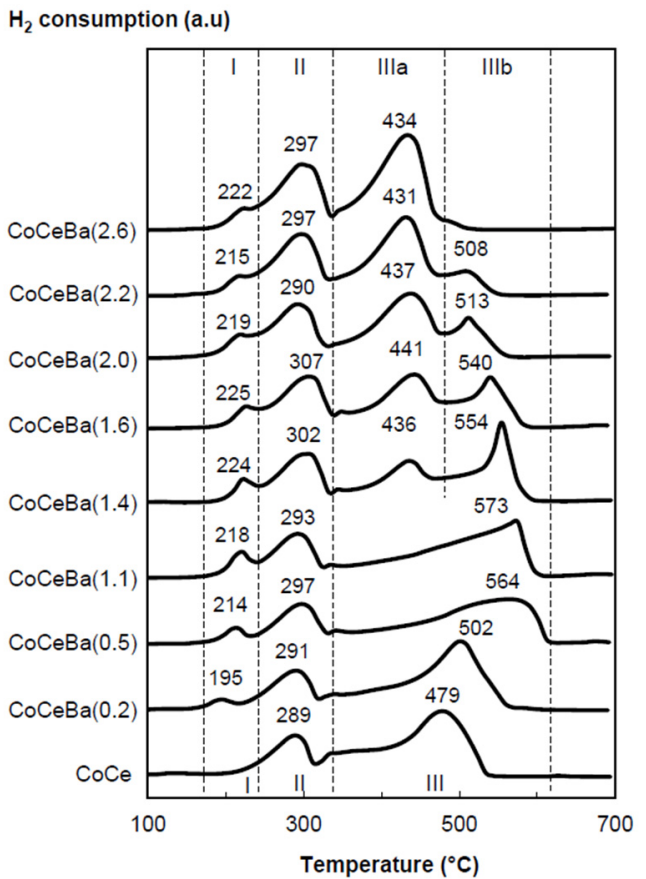

Figure 1. Reduction profiles of the cobalt catalyst promoted with cerium and with a barium loading in the range: $0-2.6 \mathrm{mmol} \mathrm{g}_{\mathrm{Co}^{-1}}$ (measurement conditions: $30-700{ }^{\circ} \mathrm{C}, 10^{\circ} \mathrm{C} \mathrm{min}^{-1}, 10 \mathrm{vol} . \% \mathrm{H}_{2} / \mathrm{Ar}$ ).

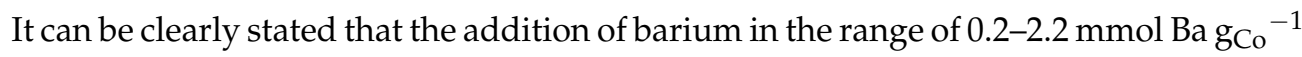
hinders the process of the CoCeBa catalysts reduction. It requires a longer time and ends at a higher temperature than in the case of a sample without barium (CoCe). Additional peaks and complexity of the CoCeBa catalyst precursor reduction profiles are most likely related to the decomposition of barium salts.

\subsection{Chemisorption Characteristics of the Active Phase Surface $\left(\mathrm{H}_{2}-\mathrm{TPD}\right)$}

The profiles of hydrogen desorbing from the surface of the promoted cobalt catalysts with different barium content are presented in Figure 2. The hydrogen desorption curves obtained for the samples containing $0-1.1 \mathrm{mmol} \mathrm{Ba} \mathrm{\textrm {g } _ { \mathrm { o } }}{ }^{-1}$ consist of one broad peak in the low-temperature range $(\alpha)$, extending from about $50{ }^{\circ} \mathrm{C}$ to $550{ }^{\circ} \mathrm{C}$. Its maximum is observed at a temperature of about $170{ }^{\circ} \mathrm{C}$. In the profiles of the samples containing $1.4 \mathrm{mmol} \mathrm{Ba} \mathrm{g} \mathrm{oo}^{-1}$ and more (i.e., in the cases where barium is in molar excess to cerium), apart from the low-temperature peak $(\alpha)$, a high-temperature peak $(\beta)$ appears with a maximum in the range $520-550{ }^{\circ} \mathrm{C}$. The low-temperature peak shifts slightly towards lower temperatures as the barium content in the samples increases. In the case of the high-temperature peak, the maximum changes its position slightly. However, there is no clear trend of this change. The low-temperature signal $(\alpha)$ corresponds to the desorption 
of hydrogen weakly bound to the cobalt surface. In contrast, the high-temperature signal ( $\beta$ ) corresponds to the desorption of $\mathrm{H}_{2}$ strongly interacting with cobalt [32]. This means that samples containing barium in the content range of $0-1.1 \mathrm{mmol} \mathrm{Ba} \mathrm{gCo}^{-1}$ have only weak hydrogen-binding sites on their surface. In contrast, on the surface of cobalt in the samples containing $1.4 \mathrm{mmol} \mathrm{Ba} \mathrm{gCo}^{-1}$ and more, both weakly and strongly hydrogenbinding sites coexist. As the barium content increases, the intensity of the low-temperature peak decreases. The area ratio $(\beta / \alpha$, Table 2$)$ of peaks corresponding to strongly and weakly-binding sites on the surface of catalysts increases with barium content above $1.4 \mathrm{mmol} \mathrm{Ba} \mathrm{C}_{\mathrm{Co}}{ }^{-1}$, and reaches the highest value for the $\mathrm{CoCeBa}(2.2)$ system. Moreover, for the two systems with the highest barium content, $\mathrm{CoCeBa}(2.2)$ and $\mathrm{CoCeBa}(2.6)$, the high-temperature $(\beta)$ peak begins to dominate the low-temperature $(\alpha)$ one in terms of the area. The observed phenomena, i.e., peak sharpening, slight temperature shifts of their location, appearance of new peaks, indicate the restructuration of the cobalt systems surface, occurring with the increase in barium content. Not only does the number of hydrogen-binding sites change, but the homogenization of their energy and formation of new types of sites also becomes visible. Therefore, it may be stated that these results support the conclusion that barium exhibits the role of a structural promoter in the studied cobalt catalysts.

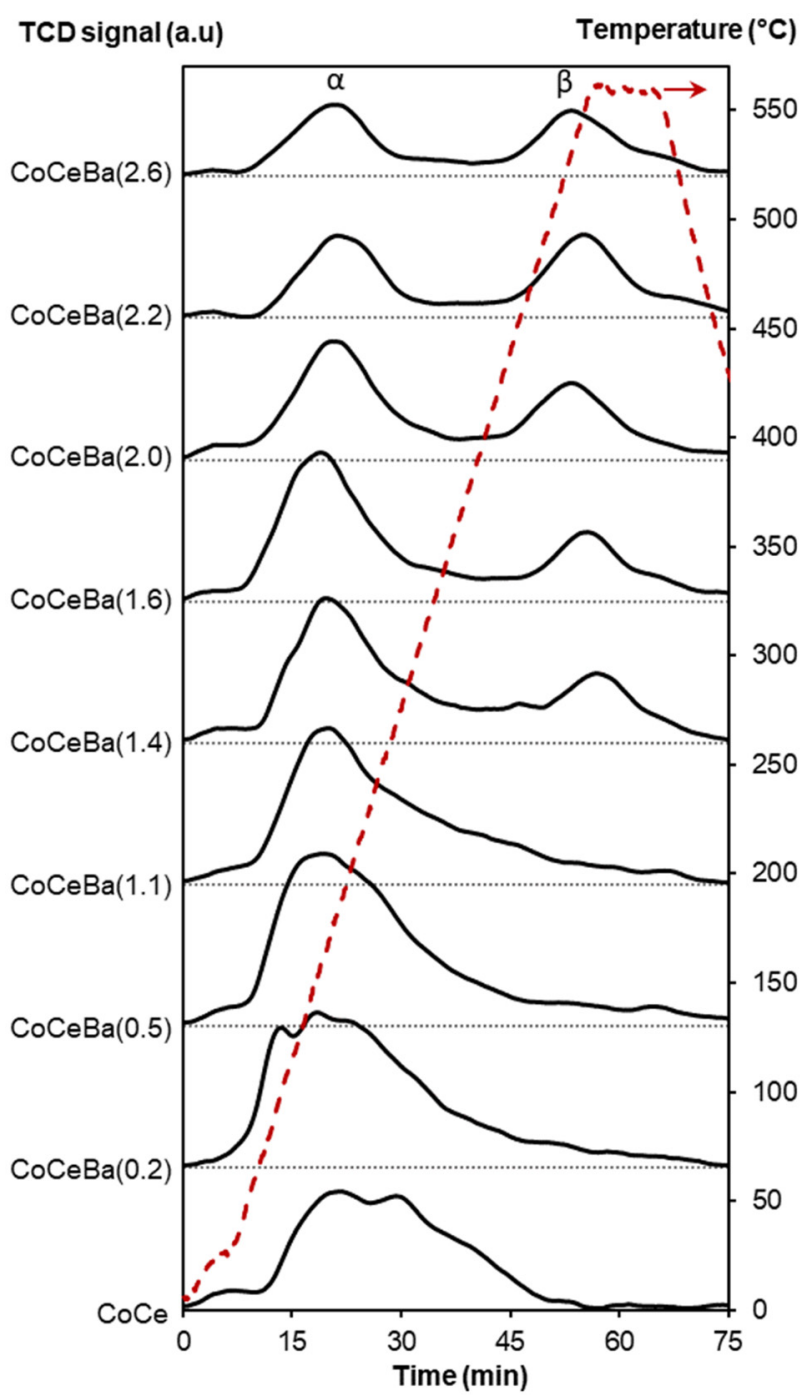

Figure 2. Profiles of hydrogen desorption from the surface of the cobalt catalyst promoted with cerium and with a barium loading in the range: $0-2.6 \mathrm{mmol}_{\mathrm{Co}}{ }^{-1}$. 
Table 2. Chemisorption characteristics of the promoted cobalt catalysts.

\begin{tabular}{|c|c|c|c|c|c|}
\hline \multirow{2}{*}{ Catalyst } & \multicolumn{2}{|c|}{$\mathrm{H}_{2}$ Uptake $\left(\mu \mathrm{mol} \mathrm{g}_{\mathrm{Co}}{ }^{-1}\right)$} & \multirow{2}{*}{$\beta / \alpha$ Peak Area Ratio } & \multirow{2}{*}{$\mathrm{S}_{\mathrm{Co}}{ }^{1}\left(\mathrm{~m}^{2} \mathrm{~g}_{\mathrm{Co}}{ }^{-1}\right)$} & \multirow{2}{*}{$\mathrm{d}_{\mathrm{Co}-\mathrm{TPD}}{ }^{2}(\mathrm{~nm})$} \\
\hline & $\alpha$ Peak & $\beta$ Peak & & & \\
\hline $\mathrm{CoCe}$ & 121.4 & - & - & 7.7 & 88 \\
\hline $\mathrm{CoCeBa}(0.2)$ & 162.5 & - & - & 10.3 & 66 \\
\hline $\mathrm{CoCeBa}(0.5)$ & 160.8 & - & - & 10.2 & 66 \\
\hline $\mathrm{CoCeBa}(1.1)$ & 154.4 & - & - & 9.8 & 69 \\
\hline $\mathrm{CoCeBa}(1.4)$ & 100.1 & 61.4 & 0.6 & 10.2 & 66 \\
\hline $\mathrm{CoCeBa}(1.6)$ & 102.7 & 59.4 & 0.6 & 10.2 & 66 \\
\hline $\mathrm{CoCeBa}(2.0)$ & 83.2 & 62.9 & 0.8 & 9.2 & 73 \\
\hline $\mathrm{CoCeBa}(2.2)$ & 46.5 & 65.0 & 1.4 & 7.1 & 96 \\
\hline $\mathrm{CoCeBa}(2.6)$ & 43.6 & 48.0 & 1.1 & 5.6 & 117 \\
\hline
\end{tabular}

${ }^{1} \mathrm{~S}_{\mathrm{Co}}$-surface area of the active phase (cobalt) estimated based on $\mathrm{H}_{2}$-TPD measurement results.

${ }^{2} \mathrm{~d}_{\mathrm{Co}-\mathrm{TPD}}$-average cobalt particle size estimated based on $\mathrm{H}_{2}$-TPD measurement results.

Based on the hydrogen desorption curves (Figure 2) and calculated $\mathrm{H}_{2}$ uptake (Table 2), the average size of metallic cobalt particles $\left(\mathrm{d}_{\mathrm{Co}-\mathrm{TPD}}\right)$ and the active phase surface area $\left(\mathrm{S}_{\mathrm{Co}}\right)$ were determined. The data presented in Table 2 show that even a small addition of the barium promoter $\left(0.2 \mathrm{mmol} \mathrm{Ba} \mathrm{gCo}^{-1}\right)$ results in a significant, i.e., about $33 \%$, increase in the active phase surface, compared to that of the catalyst without the barium promoter (sample

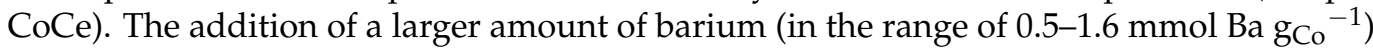
does not significantly change the Co surface area-for all these systems, the $\mathrm{S}_{\mathrm{Co}}$ value is constant and amounts to approx. $10 \mathrm{~m}^{2} \mathrm{~g}_{\mathrm{Co}}{ }^{-1}$. However, a further increase in the content

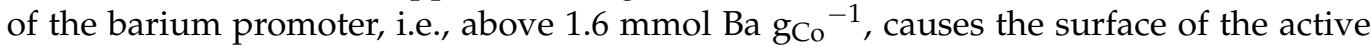
phase to gradually decrease. The largest cobalt particle size $\left(\mathrm{d}_{\mathrm{Co}-\mathrm{TPD}}\right)$ was determined, and thus the lowest metallic cobalt surface $\left(\mathrm{S}_{\mathrm{Co}}\right)$ was observed for $\mathrm{CoCeBa}(2.6)$, which has the highest Ba content.

\subsection{Phase Composition of the Precursors and Catalysts in the Reduced form (XRPD)}

The phase composition of the selected promoted cobalt catalysts was analyzed using XRPD. The materials in the oxidized (catalyst precursors) and reduced (catalysts) forms were investigated. The recorded diffraction patterns are presented in Figure 3. Reflexes from $\mathrm{Co}_{3} \mathrm{O}_{4}$ are visible in the diffraction patterns of all oxidized samples (Figure 3a). However, there are no reflexes from $\mathrm{CeO}_{2}$. This may indicate the presence of a weakly crystallized or amorphous and/or highly dispersed cerium oxide. The presence of signals from two different Ba-containing phases is observed. Barium nitrate signals are clearly visible for the samples with high barium content. Barium nitrate was used for impregnation and the introduction of a substantial amount of this salt could cause a crystallization of this compound in the form of larger particles, detectable by XRPD. For the samples with low barium content, the amount of salt could be too small to form particles of a size appropriate for XRPD analysis or they were better dispersed within the samples. For the catalysts in the reduced form (Figure $3 \mathrm{~b}$ ), signals derived from $\mathrm{Ba}\left(\mathrm{NO}_{3}\right)_{2}$ are not detected. According to the literature reports [33], $\mathrm{Ba}\left(\mathrm{NO}_{3}\right)_{2}$ is transformed into amorphous $\mathrm{BaO}_{\mathrm{x}}$ species under ammonia synthesis reaction conditions. The subsequent reaction of $\mathrm{BaO}_{x}$ species with atmospheric $\mathrm{CO}_{2}$ could cause the formation of $\mathrm{BaCO}_{3}$ particles (exsitu XRPD measurements for the catalyst samples removed from the ammonia synthesis reactor). Drying barium nitrate at $120{ }^{\circ} \mathrm{C}$ should not cause the decomposition of the compound. According to the author of [34], the decomposition of pure barium nitrate occurs above $530{ }^{\circ} \mathrm{C}$. Nevertheless, the dispersion of barium nitrate on the surface of another material significantly lowers the decomposition temperature. During drying of the catalyst precursors, the dispersed salt could presumably be partially decomposed into $\mathrm{BaO}$, and due to contact with air (containing $\mathrm{CO}_{2}$ ), it could transform into $\mathrm{BaCO}_{3}$. Hence, there are visible signals of this phase in the catalyst precursor samples (Figure 3a). 
(a)

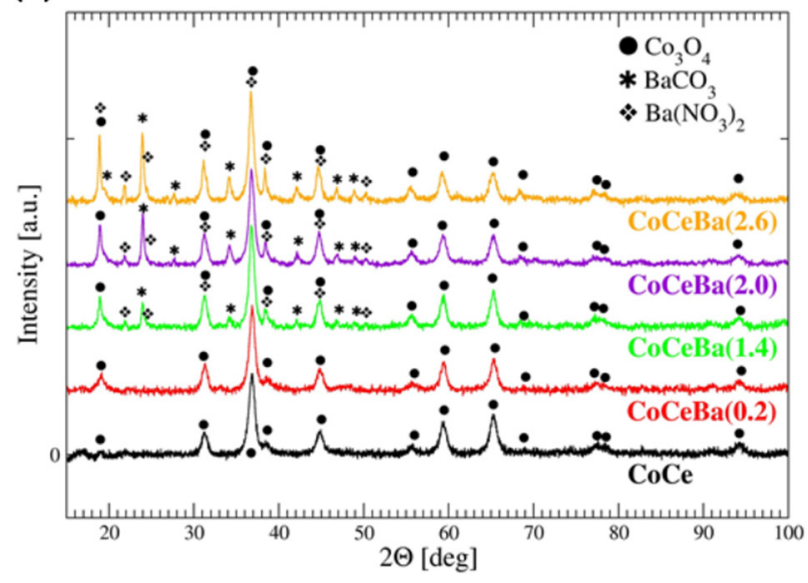

(b)

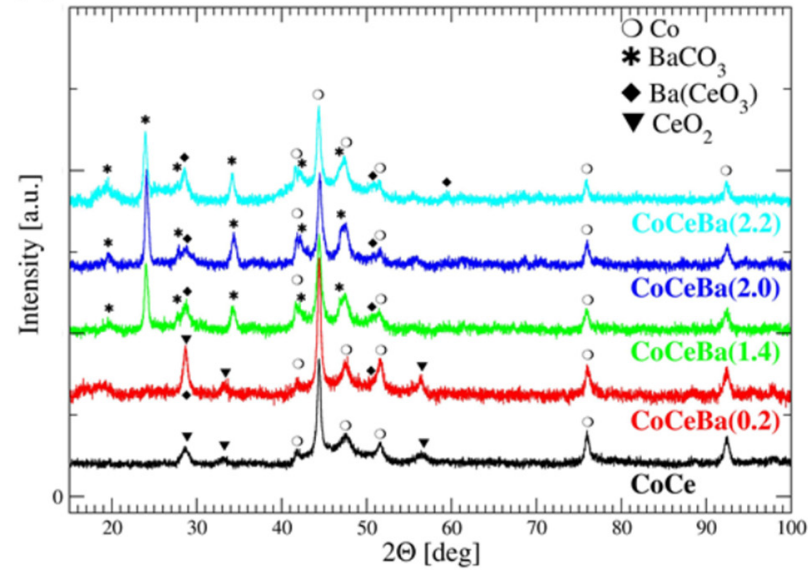

Figure 3. XRPD patterns of the cobalt catalysts promoted with cerium $(\mathrm{CoCe})$ or cerium and barium $(\mathrm{CoCeBa})$ in the form of a precursor $(\mathbf{a})$ and the reduced form $(\mathbf{b})$.

In the case of reduced samples, metallic cobalt is observed (Figure 3b). There are visible signals typical for hexagonal close-packed cobalt (Co hcp: $41.6^{\circ}$ and $47.5^{\circ}$ ) and face-centered cubic cobalt $\left(\mathrm{Co}\right.$ fcc, $\left.51.5^{\circ}\right)$. The reflexes at the $2 \theta$ angles $=44.4^{\circ}, 75.9^{\circ}$, and $92.4^{\circ}$ may come from both phases-Co hcp and Co fcc. It is also worth noting that the form of promoter results from the interaction between barium and cerium compounds in the samples. In $\mathrm{CoCeBa}(0.2)$, the cerium promoter is present in the form of two chemical compounds: cerium oxide $\left(\mathrm{CeO}_{2}\right)$ and barium cerate $\left(\mathrm{BaCeO}_{3}\right)$, whereas barium is only observed in the form of $\mathrm{BaCeO}_{3}$. As indicated in Table 1, in sample CoCeBa(0.2), cerium is present in molar excess to barium, so the phase composition determined by XRPD is consistent with the chemical composition. For other samples (i.e., $\mathrm{CoCeBa}(1.4), \mathrm{CoCe}(2.0)$, and $\mathrm{CoCeBa}(2.2)$ ), where the $\mathrm{Ba} / \mathrm{Ce}$ molar ratio is greater than unity (Table 1$)$, no cerium oxide phase is observed, as Ce is likely to be bound entirely in the form of barium cerate.

Based on the results obtained from XRPD measurements, the average cobalt oxide crystallite size $\left(\mathrm{d}_{\mathrm{Co3O}} \mathrm{O}-\mathrm{XRD}\right)$ for the precursor samples and the average metal cobalt crystallite size $\left(\mathrm{d}_{\mathrm{Co}-\mathrm{XRD}}\right)$ for the reduced samples (ex-situ measurements) were estimated and are presented in Table 3 . The average size of cobalt oxide crystallites $\left(\mathrm{d}_{\mathrm{Co} 3 \mathrm{O} 4-\mathrm{XRD}}\right)$ in all the samples is similar and equals approx. $11 \mathrm{~nm}$. This result may suggest that barium has no structure-forming effect on cobalt in the case of oxidized materials, i.e., it does not increase or decrease the surface area of the cobalt oxide. The estimated average crystallite size of the metallic cobalt in the reduced samples $\left(\mathrm{d}_{\mathrm{Co}-\mathrm{XRD}}\right)$ are also similar (in the range of $21-26 \mathrm{~nm}$ ) and much lower than the $\mathrm{d}_{\mathrm{Co} \text {-TPD }}$ values calculated based on the chemisorption measurements (Table 2). This may be because the XRPD method can determine small cobalt crystallites, structurally ordered fragments of larger aggregates (agglomerates). However, during chemisorption measurements, only the outer surface of the particles is available for the adsorbate. Consequently, the values of $\mathrm{d}_{\mathrm{CO}-\mathrm{TPD}}$ related to cobalt particles may be greater than the values of $\mathrm{d}_{\mathrm{Co}-\mathrm{XRD}}$ related to cobalt crystallites.

\subsection{Morphology and Element Distribution of the Catalysts in the Reduced form (SEM-EDX)}

Figure 4 contains SEM images of the selected catalysts in the reduced form. They show that the morphology of $\mathrm{CoCe}$ and $\mathrm{CoCeBa}(0.2)$ samples is similar. Both materials consist of nanoparticles formed into larger grains. Although the images show the surface morphology regardless of its composition, they confirm previous observations and conclusions drawn for the active phase of the catalyst from $\mathrm{H}_{2}$-TPD and XRPD analyses (Table 2- $\mathrm{d}_{\mathrm{Co}-\mathrm{TPD}}$ values and Table $3-\mathrm{d}_{\mathrm{Co}-\mathrm{XRD}}$ values, respectively). It was then found that the differences observed between the cobalt crystallite sizes estimated based on these two methods result from the fact that the crystallites of the active phase with an ordered crystal structure (detectable by the XRPD method) may aggregate into larger particles (agglomerates). Their 
size resulting from the development of their external surface, accessible to gaseous probe molecules, is estimated based on $\mathrm{H}_{2}$-TPD data. The SEM analysis also confirms that $\mathrm{CoCeBa}(1.4)$ is a catalyst with a well-developed surface. In fact, it has the most developed surface among the samples tested with this method, which is in good agreement with the results of textural studies of the reduced form of this sample. It can also be seen (Figure 4) that $\mathrm{CoCeBa}(2.2)$ differs in morphology from the other samples due to high barium content. The particles which form the grains of the catalyst containing $2.2 \mathrm{mmol} \mathrm{Ba} \mathrm{gCo}^{-1}$ are much larger than in the case of the other tested catalysts. Consequently, the sample's surface is smaller, i.e., less developed. These observations are also consistent with the results of the specific surface area after reduction (Table $1-S_{R}$ values) and active phase surface area (Table 2, $\mathrm{S}_{\mathrm{Co}}$ values) obtained for the studied catalysts.

Table 3. The crystallite sizes of Co-containing phases of the promoted cobalt catalysts.

\begin{tabular}{ccc}
\hline Catalyst & $\mathbf{d}_{\text {Co3O4-XRD }} \mathbf{~}^{\mathbf{1}} \mathbf{( n \mathbf { m } )}$ & $\mathbf{d}_{\mathbf{C o}-\mathbf{X R D}}{ }^{\mathbf{2}} \mathbf{( n m )}$ \\
\hline $\mathrm{CoCe}$ & 10 & 22 \\
$\mathrm{CoCeBa}(0.2)$ & 11 & 24 \\
$\mathrm{CoCeBa}(1.4)$ & 12 & 21 \\
$\mathrm{CoCeBa}(2.0)$ & 11 & 21 \\
$\mathrm{CoCeBa}(2.2)$ & - & 26 \\
$\mathrm{CoCeBa}(2.6)$ & 10 & - \\
\hline
\end{tabular}

1 The mean cobalt oxide crystallite size $\left(\mathrm{d}_{\mathrm{C} O 3 \mathrm{O} 4-\mathrm{XRD}}\right)$ for the precursor samples. ${ }^{2}$ The mean metal cobalt crystallite size $\left(\mathrm{d}_{\mathrm{Co}-\mathrm{XRD}}\right)$ for the reduced samples (ex-situ measurements).
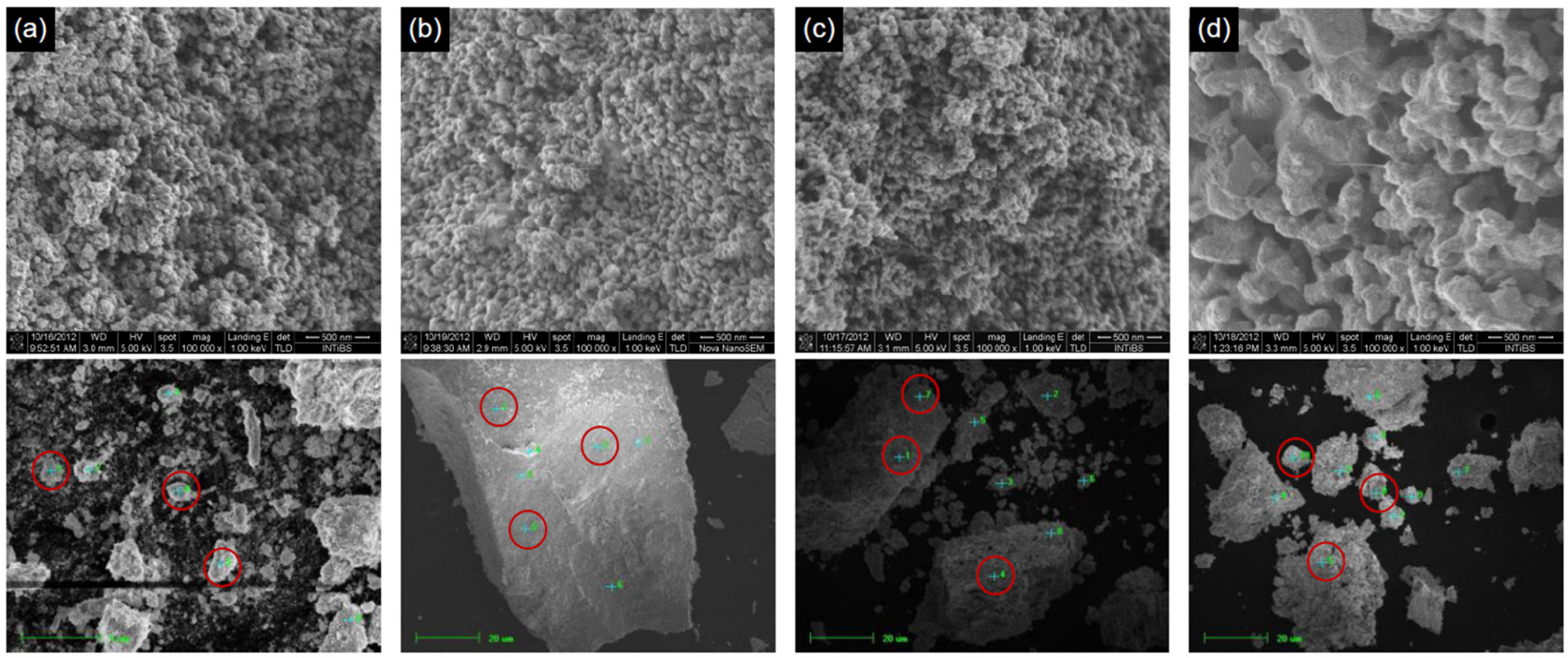

Figure 4. SEM images and corresponding BSE images of selected promoted cobalt catalysts in the reduced form (ex-situ measurement): (a) $\mathrm{CoCe},(\mathbf{b}) \mathrm{CoCeBa}(0.2)$, (c) $\mathrm{CoCeBa}(1.4),(\mathbf{d}) \mathrm{CoCeBa}(2.2)$. The selected grains taken into account in the element distribution analysis (EDX) are marked in red.

The distribution of $\mathrm{Co}, \mathrm{Ce}$, and Ba elements on the surface of the tested catalyst samples in their reduced form was determined using EDX analysis. The results of the relative ratios of the elements in three randomly selected points (Figure 4) on the surface of the samples are presented in Table 4. In all the tested catalysts, at each of the selected measuring points, the Co/Ce ratio is similar, which indicates a uniform distribution of cobalt and cerium on the catalyst surface. This is due to the preparation of the catalyst precursor by co-precipitation, which ensures a good distribution of the cerium promoter throughout the sample. However, in the Ba-promoted samples, the distribution of barium with respect to cobalt is not uniform. The $\mathrm{Co} / \mathrm{Ba}$ ratio discrepancies between selected points may be due to the method of sample preparation, i.e., incipient wetness impregnation method, which does not ensure uniform deposition of the promoting element on the catalyst surface. 
Table 4. Distribution of $\mathrm{Co}, \mathrm{Ce}$, and Ba (relative ratio of the elements in three randomly selected points) on the surface of the promoted cobalt catalysts.

\begin{tabular}{ccccccc}
\hline \multirow{2}{*}{ Catalyst } & Point & \multicolumn{3}{c}{ Element Share (\%) } & \multicolumn{2}{c}{ Elements Ratio } \\
\cline { 2 - 6 } & & Co & Ce & Ba & Co/Ce & Co/Ba \\
\hline \multirow{2}{*}{ CoCe } & 1. & 88.5 & 11.5 & - & 7.7 & - \\
& 2. & 88.4 & 11.6 & - & 7.6 & - \\
& 3. & 88.0 & 12.0 & - & 7.3 & - \\
$\operatorname{CoCeBa}(0.2)$ & 1. & 85.7 & 11.3 & 3.0 & 7.6 & 28.6 \\
& 2. & 86.8 & 11.5 & 1.7 & 7.5 & 51.1 \\
$\operatorname{CoCeBa}(1.4)$ & 3. & 85.6 & 11.3 & 3.1 & 7.6 & 27.6 \\
& 1. & 79.4 & 9.0 & 11.7 & 8.8 & 6.8 \\
$\operatorname{CoCeBa}(2.2)$ & 2. & 77.9 & 9.1 & 13.0 & 8.6 & 6.0 \\
& 3. & 69.2 & 7.8 & 23.0 & 8.9 & 3.0 \\
& 1. & 79.1 & 9.9 & 11.1 & 8.0 & 7.1 \\
& 2. & 75.3 & 8.8 & 15.9 & 8.6 & 4.7 \\
& 3. & 51.5 & 6.3 & 2.2 & 8.2 & 23.4 \\
\hline
\end{tabular}

\subsection{Activity in $\mathrm{NH}_{3}$ Synthesis (Catalytic Activity Measurements)}

Measurements of the catalyst activity were carried out, and the average reaction rate ( $\mathrm{r}_{\mathrm{av}}$ ) of ammonia synthesis was determined. Based on $\mathrm{r}_{\mathrm{av}}$ values and $\mathrm{H}_{2}$ uptake values (from $\mathrm{H}_{2}$-TPD measurements), the surface activity of the catalyst, expressed as the turnover frequency (TOF), was determined. The results are shown in Figure 5.

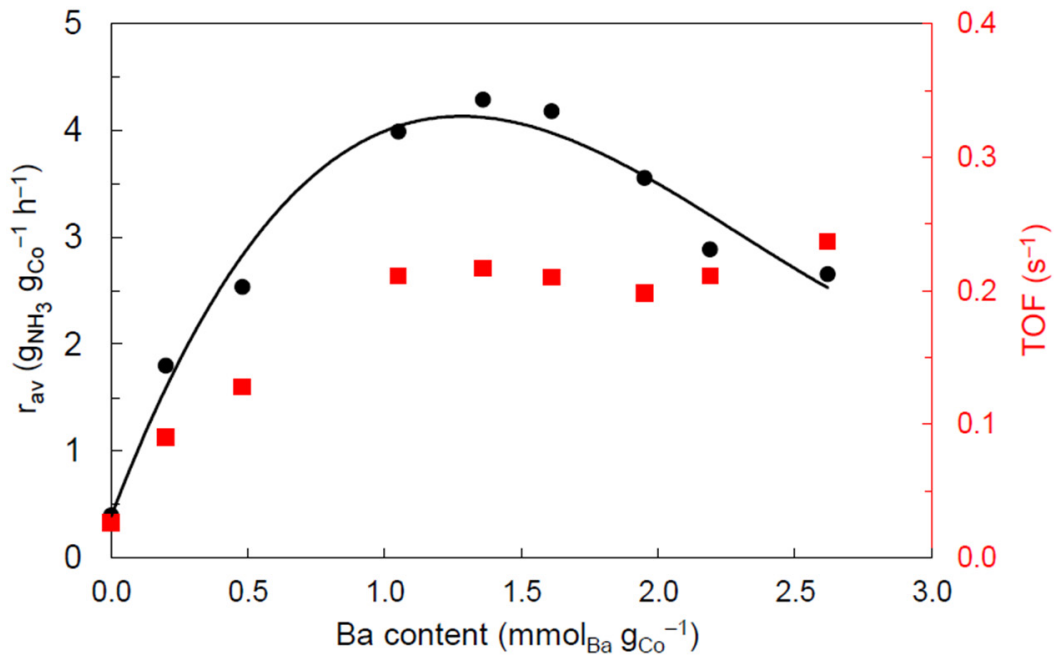

Figure 5. Dependence of activity of the promoted cobalt catalysts on the barium promoter content. Activity expressed as an average $\mathrm{NH}_{3}$ synthesis reaction rate $\left(\mathrm{r}_{\mathrm{av}}, \bullet\right)$ and TOF ( $\left.\square\right)$; measurement conditions: $\mathrm{T}=400{ }^{\circ} \mathrm{C}, \mathrm{p}=6.3 \mathrm{MPa}, \mathrm{H}_{2} / \mathrm{N}_{2}=3$; TOF was determined based on $\mathrm{r}_{\mathrm{av}}$ values and the hydrogen chemisorption data.

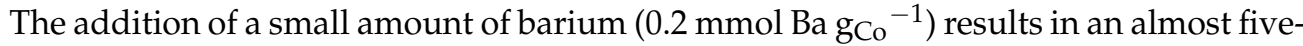
fold increase in average reaction rate and a 3.5 -fold increase in the TOF value, compared to the catalysts without barium $(\mathrm{CoCe})$. With a further increase in barium content, i.e., in the range of $0.2-1.4 \mathrm{mmol} \mathrm{Ba} \mathrm{g}_{\mathrm{Co}}{ }^{-1}$, the $\mathrm{r}_{\mathrm{av}}$ value increases, which may be a direct result of the development of the cobalt surface $\left(\mathrm{S}_{\mathrm{Co}}\right.$, Table 2$)$ in the catalysts. The average reaction rate $\left(\mathrm{r}_{\mathrm{av}}\right)$ reaches a maximum value for $\mathrm{CoCeBa}(1.4)$, and decreases with a further increasing of the barium content. The gradual increase in the activity with the addition of the barium promoter is a result of an electronic effect of barium. Its presence causes a donation of electrons to the cobalt surface, which then facilitates the cleavage of adsorbed dinitrogen. This function of the alkaline dopant was also indicated in our previous studies of the discussed cobalt systems $[15,27,35]$, other cobalt catalysts $[17,36,37]$, and ruthenium 
catalysts for ammonia synthesis [2,11,12,19-24]. Moreover, it is worth nothing that no sign of deactivation of the studied catalysts was observed after overheating $\left(600^{\circ} \mathrm{C}, 72 \mathrm{~h}\right)$, indicating that all the catalysts display stable performance-a critical parameter, especially in industrial processes. When analyzing the surface activity of the catalysts, it should be noted that the TOF value initially increases with increasing barium content in the samples. Then, for samples containing barium in the range of 1.1-2.6 mmol Ba $\mathrm{gCo}^{-1}$, it reaches a constant value of approx. $0.2 \mathrm{~s}^{-1}$. Thus, the decrease in the average reaction rate observed for the samples with the highest barium content may be related to the substantial decrease of the active phase surface $\left(\mathrm{S}_{\mathrm{Co}}\right.$, Table 2$)$.

The superior performance of the $\mathrm{CoCeBa}(1.4)$ catalyst for ammonia synthesis is revealed by comparison to the literature results with similar reaction conditions (Table 5). It can be seen that the ruthenium catalysts display higher $\mathrm{NH}_{3}$ synthesis rates, compared to the iron and cobalt catalysts. However, the activity of the $\mathrm{CoCeBa}(1.4)$ catalyst is much higher than that of the commercial fused iron catalyst (about three-fold). Thus, it might be considered as a valuable alternative to the iron catalyst for ammonia synthesis.

Table 5. The comparison of $\mathrm{NH}_{3}$ synthesis rate $\left(\mathrm{r}_{\mathrm{NH}}\right)$ over cobalt, iron, and ruthenium catalysts under the pressure of about $6 \mathrm{MPa}$ and $400^{\circ} \mathrm{C}$.

\begin{tabular}{ccc}
\hline Catalyst & $\mathbf{r}_{\mathbf{N H} 3}\left(\mathbf{g}_{\mathrm{NH} 3} \mathbf{g}_{\text {cat }}{ }^{-\mathbf{1}} \mathbf{h}^{-\mathbf{1}}\right)$ & Reference \\
\hline $\mathrm{Fe}$ & 1.2 & {$[11]$} \\
$\mathrm{Co} @ \mathrm{BaO} / \mathrm{MgO}-700$ red & 3.1 & {$[38]$} \\
$\mathrm{Ru} / \mathrm{CeO}_{2}$ & 5.4 & {$[39]$} \\
$\mathrm{K}-\mathrm{Ru} / \mathrm{C}$ & 4.4 & {$[11]$} \\
$\mathrm{CoCeBa}(1.4)$ & 3.4 & This work \\
\hline
\end{tabular}

Summarizing the presented results, it should be stated that the catalytic properties of the cobalt systems doubly promoted with cerium and barium strictly depend on the content of barium. When the cerium promoter is present in molar excess to barium $(\mathrm{Ba} / \mathrm{Ce}<1$, Table 1), barium acts as a typical structural promoter. It prevents the sintering of cobalt particles during reduction, causing the development of the active phase surface and thus an increase in the activity of the catalysts in ammonia synthesis. However, in cases where the barium to cerium ratio is greater than unity $(\mathrm{Ba} / \mathrm{Ce}>1$, Table 1$)$, the modifying (electronic) character of the barium promoter is also revealed. It was observed that despite the decrease in cobalt surface, the surface activity (TOF values) of the catalysts containing more than $1.4 \mathrm{mmol} \mathrm{Ba} \mathrm{gCo}^{-1}$ remained at a high and stable level. However, considering our previous investigation of the synergistic effect of the cerium and barium promoters in the cobalt catalyst $[15,28]$, the properties of the cobalt-cerium-barium systems should also be related to the presence of the $\mathrm{BaCeO}_{3}$ phase. For barium-rich catalysts $(\mathrm{Ba} / \mathrm{Ce}>1)$, the binding of the entire cerium promoter in the form of $\mathrm{BaCeO}_{3}$ ensures that in all these systems, the amount of this third promoter, which exhibits a strong electron- donating effect on the cobalt surface, is similar. This is reflected by the nearly constant TOF value, indicating a similar surface activity of the active phase of these materials. The lack of a free cerium promoter in the form of $\mathrm{CeO}_{2}$ (i.e., not bound in $\mathrm{BaCeO}_{3}$ ) causes the decay of the structural influence of cerium, which explains the decrease in the active phase surface area (Table 2). The effect of the decrease in the cobalt surface for the barium-rich catalysts may also be associated with the phenomenon of surface enrichment with barium, in which the barium promoter introduced in excess in relation to cerium may accumulate on the cobalt particles, blocking the access of the reagents to the active sites of the catalyst. This phenomenon was previously observed in our studies of cobalt systems promoted with barium [36]. Based on the results of the conducted experiments, the optimal barium promoter content in the CoCeBa catalyst was established. The most favorable properties were obtained for the catalytic systems containing 1.1-1.6 mmol Ba $\mathrm{gCo}^{-1}$. 


\section{Materials and Methods}

\subsection{Preparation of the Catalysts}

In the first step, a mixture of cobalt and cerium oxides $\left(\mathrm{Co}_{3} \mathrm{O}_{4}+\mathrm{CeO}_{2}\right)$ was prepared using the co-precipitation method and subsequent calcination. Appropriate amounts of cobalt(II) nitrate hexahydrate and cerium(III) nitrate hexahydrate were dissolved in distilled water. Excess potassium carbonate aqueous solution was slowly added under continuous stirring to the nitrates solution until the $\mathrm{pH}$ was 9 . Both of the solutions were first heated to $90^{\circ} \mathrm{C}$. The obtained precipitate was filtered and washed with cold distilled water until the $\mathrm{pH}$ was neutral. It was then dried at $120^{\circ} \mathrm{C}$ in air for $18 \mathrm{~h}$ and calcined at $500{ }^{\circ} \mathrm{C}$ in air for $18 \mathrm{~h}$. Afterwards, the material was impregnated with various amounts of barium using an aqueous solution of barium(II) nitrate (incipient wetness impregnation) and dried in air at $120^{\circ} \mathrm{C}$. Finally, the samples were crushed and sieved to obtain grain size in the range of $0.20-0.63 \mathrm{~mm}$. The last step of catalyst preparation was the reduction of precursors carried out directly before measurements, which required a reduced form of the materials and before the catalytic activity studies (details can be found below in a characterization methods description, Section 3.2.). As a result, a series of doubly promoted cobalt catalysts were obtained of cerium content equal to $1.1 \mathrm{mmol} \mathrm{g}_{\mathrm{Co}}{ }^{-1}$, while the barium content varied in the range of $0-2.6 \mathrm{mmol} \mathrm{g}_{\mathrm{Co}^{-}}{ }^{-1}$. Cerium content was determined using thermal analysis coupled with mass spectrometry according to the methodology described in [40] for the precursor containing only $\mathrm{Co}_{3} \mathrm{O}_{4}$ and $\mathrm{CeO}_{2}$ (i.e., the precursor before impregnation with barium). The basis of the discussed method is the fact that under the measurement conditions (heating in argon), cerium oxide is stable, whereas cobalt (II,III) oxide decomposes to cobalt (II) oxide at a temperature of about $750{ }^{\circ} \mathrm{C}$. The recorded mass loss allows the determination of the $\mathrm{Co}_{3} \mathrm{O}_{4}$ content in a mixed oxide system. The rest of the sample consists of $\mathrm{CeO}_{2}$. The content of barium promoter in the final precursor samples (before reduction) was calculated based on the mass balance before and after impregnation with barium salt of the precursor samples containing $\mathrm{Co}_{3} \mathrm{O}_{4}$ and $\mathrm{CeO}_{2}$. Barium content and a molar ratio of barium to cerium are listed in Table 1 . Materials are denoted as $\mathrm{CoCeBa}(\mathrm{n})$, where $\mathrm{n}$ is the amount of barium in relation to cobalt, as indicated in Table 1 . The sample without barium, donated as $\mathrm{CoCe}$, was a reference material.

\subsection{Catalyst Characterisation}

The specific surface area of the precursors (i.e., materials in the unreduced form), total pore volume, and specific surface area of the reduced form of the selected materials were determined by nitrogen physisorption with an ASAP2020 instrument (Micromeritics Instrument Co., Norcross, GA, USA). Before the measurements, each sample of the precursors was degassed in vacuum in two stages: at $90^{\circ} \mathrm{C}$ for $1 \mathrm{~h}$ and then at $200{ }^{\circ} \mathrm{C}$ for $4 \mathrm{~h}$. Before the measurement for the selected materials in their reduced form, the precursors were reduced in-situ at $550{ }^{\circ} \mathrm{C}$ for $10 \mathrm{~h}$ in hydrogen flow and then subjected to degassing at $150{ }^{\circ} \mathrm{C}$ for $2 \mathrm{~h}$. The reduction and degassing were conducted in the apparatus directly before $\mathrm{N}_{2}$ physisorption measurements.

The morphology and element distribution for the selected catalytic materials in the reduced form was studied using scanning electron microscopy (SEM) coupled with energydispersive X-ray spectroscopy EDX (FEI NovaNanoSEM 230, FEI Company, Hillsboro, OR, USA).

The phase composition of the selected precursors and the catalysts in the reduced form were determined using X-ray powder diffraction (XRPD). Data were collected with a Rigaku-Denki Geigerflex (Rigaku Denki Co., Ltd., Tokyo, Japan) diffractometer in BragBrentano configuration using $\mathrm{CuK} \alpha$ radiation. The samples were scanned in a $2 \theta$ range of $15-100^{\circ}$ with a step of $0.02^{\circ}$ and counting time $5 \mathrm{~s}$. The average size of $\mathrm{Co}_{3} \mathrm{O}_{4}$ crystallites (in the precursors) and metallic cobalt crystallites (in the reduced catalysts) was estimated based on the Scherrer equation using the integral width of the reflex filled to the analytical Pearson VII function. 
A reducibility of the catalyst precursors was studied using Temperature-Programmed Reduction with hydrogen $\left(\mathrm{H}_{2}\right.$-TPR) at AutoChem2920 (Micromeritics Instrument Co.). Samples of the precursors containing about $0.03 \mathrm{~g}$ of $\mathrm{Co}_{3} \mathrm{O}_{4}$ were heated from room temperature to $700{ }^{\circ} \mathrm{C}$ at a constant rate of $10{ }^{\circ} \mathrm{C} \mathrm{min} \mathrm{min}^{-1}$ in the flow of $10 \mathrm{vol} . \% \mathrm{H}_{2} / \mathrm{Ar}$ $\left(40 \mathrm{~mL} \mathrm{~min}^{-1}\right)$. The hydrogen consumption was measured by a Thermal Conductivity Detector (TCD).

The catalysts' active phase surface was characterized using temperature-programmed hydrogen desorption ( $\mathrm{H}_{2}$-TPD) using a PEAK-4 instrument. Measurements were conducted in a flow set-up supplied with high purity (99.99995 vol.\%) gases (total gas flow rate $40 \mathrm{~mL} \mathrm{~min}^{-1}$ ) in a quartz U-tube reactor. Samples of the catalyst precursors containing $0.5 \mathrm{~g} \mathrm{Co}_{3} \mathrm{O}_{4}+\mathrm{CeO}_{2}$ were reduced in a flow of $\mathrm{H}_{2} / \mathrm{Ar}=4: 1$ mixture $\left(40 \mathrm{~mL} \mathrm{~min}^{-1}\right)$ at $550{ }^{\circ} \mathrm{C}$ for $18 \mathrm{~h}$. The system was then flushed with flowing argon at $570{ }^{\circ} \mathrm{C}$ for $1 \mathrm{~h}$ and cooled to $150{ }^{\circ} \mathrm{C}$. The $\mathrm{H}_{2}$ adsorption was carried out at $150{ }^{\circ} \mathrm{C}$ for $15 \mathrm{~min}$, then continued during cooling of the sample to $0{ }^{\circ} \mathrm{C}$ and for $15 \mathrm{~min}$ at $0{ }^{\circ} \mathrm{C}$. After flushing with Ar to remove weakly bound molecules of $\mathrm{H}_{2}$, the temperature was increased to $550{ }^{\circ} \mathrm{C}$ at a constant rate $\left(10{ }^{\circ} \mathrm{C} \mathrm{min}^{-1}\right)$ and then kept for $10 \mathrm{~min}$ at $550{ }^{\circ} \mathrm{C}$ while monitoring the concentration of hydrogen desorbing from the surface of the catalyst. The surface area of the active phase $\left(\mathrm{S}_{\mathrm{Co}_{\mathrm{o}}}\right)$ and average cobalt particle size $\left(\mathrm{d}_{\mathrm{Co}}\right)$ were calculated assuming $\mathrm{H} / \mathrm{Co}=1$ stoichiometry of hydrogen adsorption [41].

\subsection{Catalytic Tests}

The activity of the catalysts in ammonia synthesis was tested in a tubular flow reactor under steady-state conditions $\left(6.3 \mathrm{MPa}, 400{ }^{\circ} \mathrm{C}, \mathrm{H}_{2} / \mathrm{N}_{2}=3\right.$, gas flow rate $\left.70 \mathrm{dm}^{3} \mathrm{~h}^{-1}\right)$. Before the activity measurements, samples of the catalyst precursors (grain size $0.2-0.63 \mathrm{~mm}$ ) of about $0.5 \mathrm{~g}$ were activated in a high purity $\mathrm{H}_{2} / \mathrm{N}_{2}=3$ mixture $(99.99995 \mathrm{vol} \%$., gas flow rate $30 \mathrm{dm}^{3} \mathrm{~h}^{-1}$ ) under atmospheric pressure in accordance with the temperature program: $470{ }^{\circ} \mathrm{C}$ for $72 \mathrm{~h}$, then $520^{\circ} \mathrm{C}$ for $24 \mathrm{~h}$ and finally $550{ }^{\circ} \mathrm{C}$ for $48 \mathrm{~h}$. The product concentration in the outlet gas was measured interferometrically. The catalytic activity was determined and expressed as an average $\mathrm{NH}_{3}$ synthesis reaction rate $\left(\mathrm{r}_{\mathrm{av}}\right)$. A detailed description of the set-up and the method for calculating the reaction rate was described in [42]. Moreover, the activity of the catalyst surface expressed as TOF was estimated. The calculation was based on the values of the average reaction rates $\left(\mathrm{r}_{\mathrm{av}}\right)$ and the number of active sites on the cobalt surface determined during chemisorption measurements ( $\left.\mathrm{H}_{2}-\mathrm{TPD}\right)$.

\section{Conclusions}

In summary, the influence of barium content on the physicochemical properties and catalytic activity of the cobalt catalyst doubly promoted with cerium and barium was investigated. A series of catalysts of various barium promoter content in the range of 0-2.6 mmol g $\mathrm{Co}^{-1}$ was prepared, characterized, and tested in ammonia synthesis. The dual nature of the role of the barium promoter(structural and modifying) was revealed, but it strictly depends on the barium-to-cerium molar ratio. For systems of the $\mathrm{Ba} / \mathrm{Ce}$ molar ratio lower than unity $(\mathrm{Ba} / \mathrm{Ce}<1)$, the structural character of barium was observed. It manifested itself mainly in preventing sintering of the active phase during reduction. For the best catalytic performance of the CoCeBa system, the Ba/Ce molar ratio should be greater than unity $(\mathrm{Ba} / \mathrm{Ce}>1)$, which results in not only a structural promotion of barium, but also a modifying action associated with the in-situ formation of the $\mathrm{BaCeO}_{3}$ phase. It was primarily reflected in the differentiation of weakly and strongly binding sites on the catalyst surface and changes of the cobalt surface activity (TOF). The optimal barium content in the range of $1.1-1.6 \mathrm{mmol} \mathrm{g} \mathrm{Co}^{-1}$ leads to obtaining a catalyst with the most favorable properties. Its excellent catalytic performance is ascribed to the appropriate $\mathrm{Ba} / \mathrm{Ce}$ molar ratio. It is also related to the presence of the $\mathrm{BaCeO}_{3}$ phase, which plays the role of a third promoter of a high electron-donating character. 
Author Contributions: Conceptualization, A.T., M.Z. and W.R.-P.; methodology, A.T., M.Z. and W.R.-P.; investigation, A.T., M.Z., H.R., W.P., B.M., L.K. and W.R.-P.; writing—original draft preparation, A.T. and M.Z.; writing-review and editing, M.Z., H.R. and W.R.-P.; visualization, A.T., and H.R.; supervision, M.Z.; funding acquisition, W.R.-P. All authors have read and agreed to the published version of the manuscript.

Funding: The research has been funded by The National Centre for Research and Development within The Applied Research Programme, grant No. PBS2/A1/13/2014.

Data Availability Statement: All data is available within the paper.

Acknowledgments: The authors thank Ewa Iwanek from the Faculty of Chemistry, Warsaw University of Technology, for additional proofreading and language corrections.

Conflicts of Interest: The authors declare no conflict of interest.

\section{References}

1. Tamaru:, K. The history of the development of ammonia synthesis. In Catalytic Ammonia Synthesis: Fundamentals and Practice; Jennings, J.R., Ed.; Plenum Press: New York, NY, USA, 1991; pp. 1-18.

2. Aika, K.; Hori, H.; Ozaki, A. Activation of nitrogen by alkali metal promoted transition metal I: Ammonia synthesis over ruthenium promoted by alkali metal. J. Catal. 1972, 27, 424-431. [CrossRef]

3. Kowalczyk, A.; Sentek, J.; Jodzis, S.; Mizera, E.; Góralski, J.; Paryjczak, T.; Diduszko, R. An alkali-promoted ruthenium catalyst for the synthesis of ammonia, supported on thermally modified active carbon. Catal. Lett. 1997, 45, 65-72. [CrossRef]

4. Hutchings, G.J. Promotion in Heterogeneous Catalysis: A Topic Requiring a New Approach? Catal. Lett. 2001, 75, 1-12. [CrossRef]

5. Stoltz, P. Structure and surface chemistry of industrial ammonia synthesis catalysts. In Ammonia. Catalysis and Manufacture; Nielsen, A., Ed.; Springer-Verlag: Berlin, Germany, 1995; pp. 17-102.

6. Vayenas, C.G.; Bebelis, S.; Pliangos, C.; Brosda, S.; Tsiplakides, D. Promotion in Heterogeneous Catalysis. In Electrochemical Activation of Catalysis; Kluwer Academic Publishers: New York, NY, USA, 2002; pp. 15-90.

7. Rase, H.F. Ammonia Converter. In Handbook of Commercial Catalysts: Heterogeneous Catalysts; CRC Press: Boca Raton, FL, USA, 2000; pp. 449-454.

8. Ertl, G.; Lee, S.B.; Weiss, M. Adsorption of nitrogen on potassium promoted Fe(111) and (100) surfaces. Surf. Sci. 1982, 114, 527-545. [CrossRef]

9. Strongin, D.R.; Somorjai, G.A. The effects of potassium on ammonia synthesis over iron single-crystal surfaces. J. Catal. 1988, 109, 51-60. [CrossRef]

10. Aika, K.; Kubota, J.; Kadowaki, Y.; Niwa, Y.; Izumi, Y. Molecular sensing techniques for the characterization and design of new ammonia catalysts. Appl. Surf. Sci. 1997, 121-122, 488-491. [CrossRef]

11. Raróg, W.; Kowalczyk, Z.; Sentek, J.; Składanowski, D.; Zieliński, J. Effect of K, Cs and Ba on the kinetics of $\mathrm{NH}_{3}$ synthesis over carbon-based ruthenium catalysts. Catal. Lett. 2000, 68, 163-168. [CrossRef]

12. Rossetti, I.; Pernicone, N.; Forni, L. Promoters effect in Ru/C ammonia synthesis catalyst. Appl. Catal. A 2001, 208, 271-278. [CrossRef]

13. Forni, L.; Molinari, D.; Rossetti, I.; Pernicone, N. Carbon-supported promoted Ru catalyst for ammonia synthesis. Appl. Catal. A 1999, 185, 269-275. [CrossRef]

14. Kowalczyk, Z.; Krukowski, M.; Raróg-Pilecka, W.; Szmigiel, D.; Zielinski, J. Carbon-based ruthenium catalyst for ammonia synthesis: Role of the barium and caesium promoters and carbon support. Appl. Catal. A 2003, 248, 67-73. [CrossRef]

15. Raróg-Pilecka, W.; Karolewska, M.; Truszkiewicz, E.; Iwanek, E.; Mierzwa, B. Cobalt catalyst doped with cerium and barium obtained by co-precipitation method for ammonia synthesis process. Catal. Lett. 2011, 141, 678-684. [CrossRef]

16. Hagen, S.; Barfod, R.; Fehrmann, R.; Jacobsen, C.J.H.; Teunissen, H.T.; Chorkendorff, I. Ammonia synthesis with barium-promoted iron-cobalt alloys supported on carbon. J. Catal. 2003, 214, 327-335. [CrossRef]

17. Tarka, A.; Zybert, M.; Truszkiewicz, E.; Mierzwa, B.; Kępiński, L.; Moszyński, D.; Raróg-Pilecka, W. Effect of a Barium Promoter on the Stability and Activity of Carbon-Supported Cobalt Catalysts for Ammonia Synthesis. ChemCatChem 2015, 7, $2836-2839$. [CrossRef]

18. Zhong, Z.; Aika, K. The Effect of Hydrogen Treatment of Active Carbon on Ru Catalysts for Ammonia Synthesis. J. Catal. 1998, 173, 535-539. [CrossRef]

19. Bielawa, H.; Hinrichsen, O.; Birkner, A.; Muhler, M. The Ammonia-Synthesis Catalyst of the Next Generation: Barium-Promoted Oxide-Supported Ruthenium. Angew. Chem. Int. Ed. 2001, 40, 1061-1063. [CrossRef]

20. Szmigiel, D.; Bielawa, H.; Kurtz, M.; Hinrichsen, O.; Muhler, M.; Raróg, W.; Jodzis, S.; Kowalczyk, Z.; Znak, L.; Zielinski, J. The Kinetics of Ammonia Synthesis over Ruthenium-Based Catalysts: The Role of Barium and Cesium. J. Catal. 2002, 205, 205-212. [CrossRef]

21. Hansen, T.W.; Wagner, J.B.; Hansen, P.L.; Dahl, S.; Topsøe, H.; Jacobsen, C.J.H. Atomic-Resolution in Situ Transmission Electron Microscopy of a Promoter of a Heterogeneous Catalyst. Science 2001, 294, 1508-1510. [CrossRef] 
22. Hansen, T.W.; Hansen, P.L.; Dahl, S.; Jacobsen, C.J.H. Support Effect and Active Sites on Promoted Ruthenium Catalysts for Ammonia Synthesis. Catal. Lett. 2002, 84, 7-12. [CrossRef]

23. Zeng, H.S.; Inazu, K.; Aika, K. The Working State of the Barium Promoter in Ammonia Synthesis over an Active-Carbon-Supported Ruthenium Catalyst Using Barium Nitrate as the Promoter Precursor. J. Catal. 2002, 211, 33-41. [CrossRef]

24. Truszkiewicz, E.; Raróg-Pilecka, W.; Szmidt-Szałowski, K.; Jodzis, S.; Wilczkowska, E.; Łomot, D.; Kaszkur, Z.; Karpiński, Z.; Kowalczyk, Z. Barium-promoted Ru/carbon catalyst for ammonia synthesis: State of the system when operating. J. Catal. 2009, 265, 181-190. [CrossRef]

25. Ronduda, H.; Zybert, M.; Patkowski, W.; Ostrowski, A.; Jodłowski, P.; Szymański, D.; Kępiński, L.; Raróg-Pilecka, W. A high performance barium-promoted cobalt catalyst supported on magnesium-lanthanum mixed oxide for ammonia synthesis. RSC Adv. 2021, 11, 14218-14228. [CrossRef]

26. Ronduda, H.; Zybert, M.; Patkowski, W.; Tarka, A.; Ostrowski; Raróg-Pilecka, W. Kinetic studies of ammonia synthesis over a barium-promoted cobalt catalyst supported on magnesium-lanthanum mixed oxide. J. Taiwan Inst. Chem. Eng. 2020, 114, 241-248. [CrossRef]

27. Tarka, A.; Patkowski, W.; Zybert, M.; Ronduda, H.; Wieciński, P.; Adamski, P.; Sarnecki, A.; Moszyński, D.; Raróg-Pilecka, W. Synergistic Interaction of Cerium and Barium-New Insight into the Promotion Effect in Cobalt Systems for Ammonia Synthesis. Catalysts 2020, 10, 658. [CrossRef]

28. Karolewska, M.; Truszkiewicz, E.; Mierzwa, B.; Kępiński, L.; Raróg-Pilecka, W. Ammonia synthesis over cobalt catalysts doped with cerium and barium. Effect of the ceria loading. Appl. Catal. A 2012, 445-446, 280-286. [CrossRef]

29. Lin, S.S.Y.; Kim, D.H.; Ha, S.Y. Metallic phases of cobalt-based catalysts in ethanol steam reforming: The effect of cerium oxide. Appl. Catal. A 2009, 355, 69-77. [CrossRef]

30. Lin, H.Y.; Chen, Y.W. The mechanism of reduction of cobalt by hydrogen. Mater. Chem. Phys. 2004, 85, 171-175. [CrossRef]

31. Xue, L.; Zhang, C.; He, H.; Teraoka, Y. Catalytic decomposition of $\mathrm{N}_{2} \mathrm{O}$ over $\mathrm{CeO}_{2}$ promoted $\mathrm{Co}_{3} \mathrm{O}_{4}$ spinel catalyst. Appl. Catal. $B$ 2007, 75, 167-174. [CrossRef]

32. Ronduda, H.; Zybert, M.; Patkowski, W.; Ostrowski, A.; Jodłowski, P.; Szymański, D.; Kępiński, L.; Raróg-Pilecka, W. Development of cobalt catalyst supported on $\mathrm{MgO}-\mathrm{Ln}_{2} \mathrm{O}_{3}(\mathrm{Ln}=\mathrm{La}, \mathrm{Nd}, \mathrm{Eu})$ mixed oxide systems for ammonia synthesis. Int. J. Hydrog. Energy 2022, 47, 6666-6678. [CrossRef]

33. Nishi, M.; Chen, S.Y.; Takagi, H. Mild ammonia synthesis over Ba-promoted Ru/MPC catalysts: Effect of the Ba/Ru ratio and the mesoporous structure. Catalysts 2019, 9, 480. [CrossRef]

34. Bardwell, C.J.; Bickley, R.I.; Poulston, S.; Twigg, M.V. Thermal decomposition of bulk and supported barium nitrate. Thermochim. Acta 2015, 613, 94-99. [CrossRef]

35. Patkowski, W.; Kowalik, P.; Antoniak-Jurak, K.; Zybert, M.; Ronduda, H.; Mierzwa, B.; Próchniak, W.; Raróg-Pilecka, W. On the effect of flash calcination method on the characteristics of cobalt catalysts for ammonia synthesis process. Eur. J. Inorg. Chem. 2021, 15, 1518-1529. [CrossRef]

36. Zybert, M.; Wyszyńska, M.; Tarka, A.; Patkowski, W.; Ronduda, H.; Mierzwa, B.; Kępiński, L.; Sarnecki, A.; Moszyński, D.; RarógPilecka, W. Surface enrichment phenomenon in the Ba-doped cobalt catalyst for ammonia synthesis. Vacuum 2019, $168,108831$. [CrossRef]

37. Tarka, A.; Zybert, M.; Kindler, Z.; Szmurło, J.; Mierzwa, B.; Raróg-Pilecka, W. Effect of precipitating agent on the properties of cobalt catalysts promoted with cerium and barium for $\mathrm{NH}_{3}$ synthesis obtained by co-precipitation. Appl. Catal. A 2017, $532,19-25$. [CrossRef]

38. Sato, K.; Miyahara, S.; Tsujimaru, K.; Wada, Y.; Toriyama, T.; Yamamoto, T.; Matsumura, S.; Inazu, K.; Mohri, H.; Iwasa, T.; et al. Barium Oxide Encapsulating Cobalt Nanoparticles Supported on Magnesium Oxide: Active Non-Noble Metal Catalysts for Ammonia Synthesis under Mild Reaction Conditions. ACS Catal. 2021, 11, 13050-13061. [CrossRef]

39. Fang, B.; Liu, F.; Zhang, C.; Li, C.; Ni, J.; Wang, X.; Lin, J.; Lin, B.; Jiang, L. Sacrificial Sucrose Strategy Achieved Enhancement of Ammonia Synthesis Activity over a Ceria-Supported Ru Catalyst. ACS Sustain. Chem. Eng. 2021, 9, 8962-8969. [CrossRef]

40. Zybert, M.; Truszkiewicz, E.; Mierzwa, B.; Raróg-Pilecka, W. Thermal analysis coupled with mass spectrometry as a tool to determine the cobalt content in cobalt catalyst precursors obtained by co-precipitation. Thermochim. Acta 2014, 584, 31-35. [CrossRef]

41. Reule, R.C.; Bartholomew, C.H. The stoichiometries of $\mathrm{H}_{2}$ and $\mathrm{CO}$ adsorptions on cobalt: Effects of support and preparation. J. Catal. 1984, 85, 63-77. [CrossRef]

42. Kowalczyk, Z. Effect of potassium on the high-pressure kinetics of ammonia synthesis over fused iron catalysts. Catal Lett. 1996, 37, 173-179. [CrossRef] 